\title{
MOTIVATIONAL BODYBUILDING VIDEOS AS A COMPONENT OF DISCOURSE INFLUENCING PERCEPTIONS OF MASCULINITIES
}

\author{
KACPER MADEJ $J^{1}$ \\ ${ }^{1}$ Adam Mickiewicz University in Poznań, Faculty of Sociology, Szamarzewskiego 89, 60-568 Poznań, \\ Poland. ORCID: 0000-0002-3758-2812,Email address: kacper.madej@amu.edu.pl
}

ABSTRACT: The cult of a slim and beautiful body is no longer characteristic only for women. The male body is becoming more frequently subjected to the pressure of modelling. The use of different regimes increasingly intends to fulfil the requirements of attractiveness and physical perfection, also among men and boys. The discourse of disciplining the male body and its expectations also influence socially acceptable ways of performing gender. Employing a qualitative analysis of bodybuilding motivational films' content, the author points out the key elements of the body project image in such materials. The possibility of identifying bodybuilders with experts in body modification, resulting from the specificity of the discipline, allows one to believe that the regimes and training tools presented by them can influence the perception of the body modelling process by men. The author presents four elements used to develop an image of the male body project - (1) conditions necessary for the project, (2) tools used in the project, (3) ways of controlling and evaluating the project, (4) side effects of the project. Based on them demonstrates how motivational bodybuilding films can affect changing ways of performing masculinity.

KEYWORDS: masculinity, bodybuilding, body project, body modification, male body, bodily control 


\section{INTRODUCTION}

$\mathrm{O}$ ne of the fundamental challenges for contemporary gender studies is to present femininity and masculinity to emphasize their flexibility and variability. An example of a broadly applied approach in the social sciences that underlines the individual's dynamic influence on the image of femininity and masculinity is the concept of gender performativity (West \& Zimmerman 1987; Deutsch 2007; Butler 1990). Therefore, actors can actively effect (to some extent) cultural gender codes, possibly by contesting them. This approach emphasizes the variability of expectations concerning masculinity's presentation over time and concerning different individual activity fields.

It is emphasized that all practices, activities, and ways of using, presenting, and transforming the body, are gendered. Regardless of their level of complexity and the actor's intentionality or consciousness while performing them, all individual activities (including, for example, a manner of walking) can be described in relation to masculinities or associated with them gendered expectations (Bowman 2020: 402).

Berggren (2014), while describing the ideas of post-structuralist feminism grounded in assumptions of performativity and gender non-essentialism, and referring to authors such as Foucault (1990) and Butler (1990), indicates three fundamental attributes in relation to individual subjectivity: (1) way it is constituted, (2) incoherence, and (3) opacity (Berggren 2014: 363).

(1) The constitution of subjectivity is accomplished in discourse. Different discursive formations systematically constitute the objects they address. About gender, it can therefore be assumed that the expressions that describe it in the discourse are not the consequences of the existence of masculinities (and femininities), but are actively involved in the performative constitution of this categories. (2) The discourses operating in social space are not coherent with one another. The occurrence of competition and conflict between discourses influencing the dominant ways of performing masculinity can be considered inevitable. (3) Individuals functioning in a relationship of dependence on discourses cannot entirely distance themselves from discourses, which reduces the possibility of presenting them as rational actors (Berggren 2014: 363-365).

In this article, I will refer to one of the discourses influencing the image of masculinities in contemporary society - the discourse of disciplining the male body. The analysis of this discourse enables to present the physical ideals of the gendered male body and other expected characteristics that facilitate effective modelling of the body. The process of transforming the body always takes place in norms that are derived from socially accepted gender codes. This implies that expectations towards the male body also represent expectations towards masculinities presented through this discourse.

Within the discourse of disciplining the male body, I will concentrate on its most familiar component, according to Majer (2016) - exercising in the gym. I will introduce fundamental assumptions about the body as a reflexive project (Giddens 2001), as the foundation for understanding the process of body modelling and the pressures 
to aestheticize it by men. I will then provide a characterization of men who regularly exercise at the gym (Maciejewska 2014). This will enable one to demonstrate the image of masculinity produced by long-term participants in physique exercise, who aspire to be bodybuilders, as one of the discourse's contributing parts.

In the following section of this article, I will briefly characterize bodybuilding as a form of professionalization of the process of body modelling that enables one to describe the individuals who practice the sport as experts at conducting body projects. The reference to bodybuilders potentially provides an opportunity to indicate a very explicit display of expectations of the male body (and consequently masculinities) because, as Bridges (2009: 86) suggests, athletes "make their living from displaying and performing gender".

This article aims to reconstruct the image of the male body project presented in bodybuilding motivational films as one component of the discourse of disciplining the male body. Its presentation will allow for an interpretation of the expectations associated with socially acceptable ways of performing masculinities prominent in this discourse.

\section{THE BODY AS A PROJECT}

Approaching the process of disciplining the body as a framework for presenting transformations of masculinity demands the assumption that the body can be presented as malleable, subordinate to the individual's will, and that it constitutes an essential element of the identity that the individual constructs and displays. This ensures that changes in the patterns of masculinities can be applied dynamically and that their consequences will be apparent in body transformation practices and physiques.

The body's portrayal can provide this as a reflexive project (Giddens 2001), which largely refers to the presentation of it as an element of individual identity. Therefore, it becomes a space for the expression of the self, symbolic communication and simultaneously requires work on it (Shilling 2003 in Staniec-Januszek 2019:131). The changing image of the individual's identity makes his body acquire a kind of openness. "It constitutes a space open to structuring and changes, which are the result of the individual's identity explorations and the valid cultural patterns related to corporeality." (Dziuban 2013: 79-80)

Giddens (2001:142) emphasizes that the individual is forced to update the project concerning social reality continually. The body remains in a state of constant "unfinished" or "incompletion". In regards to masculinities, this is an assumption that can cause tensions to occur. Body transformation expectations and bodily ideals that change over time can conflict with an individual's gender identity, mostly dependent on gender socialization. Being receptive to the dynamically changing attractiveness of specific images of men (and therefore the way the social environment will perceive the individual) must be continuously negotiated with the image of one's masculinity to avoid the risk of experiencing gender identity problems.

Such tensions relate to the potential dismissal of the pressures imposed on attractiveness and the inability to conform to media-presented models of the ideal body and 
the corresponding shame or fear. This is significant because the contemporary, traditional masculinity model (Arcimowicz 2015:64) and the related low level of attention accorded to bodily appearance, weight or musculature, are increasingly irrelevant. An analysis of the discourse of disciplining the male body can therefore provide a closer look at the direction of change regarding male body image and the associated transformations of masculinities.

\section{THE MALE BODY DISCIPLINING DISCOURSE}

Anna Majer (2016), by examining the discourse of disciplining the male body based on one of the portals addressed to men confirms the aforementioned direction of reflection - body modelling is primarily intended to approach the ideal of beauty. Body efficiency and strength result from improving the appearance is an indicator of valued vitality rather than its goal.

The body is expected to be clean, fresh, and washed, free of excessive hair, unpleasant smell, pustules, spots, and other skin imperfections. A big issue is a baldness. Men should also have an attractive smile, have well-maintained teeth, be young and sexually capable. For this article's purposes, fundamental are those elements on which an individual can consciously influence by performing physical exercises, i.e. good physical condition, health, lean physique, and muscularity (Majer 2016: 187-203).

A lean body usually requires the individual to impose rigour on it and to transform it adequately. This distinguishes it from the skinny figure, which in the discourse analyzed by Majer was strongly criticized as non-masculine, constituting a defect and requiring work on it. A lean body is characterized by a proportional physique, low body fat level, clearly visible but not excessive musculature. It can also be referring to the former working-class tradition, which indicates as attractive a highly developed chest and shoulders, which are primarily a symbol of physical strength (Majer 2016: 193-196).

The elements connecting the components of bodily ideals are the intentionality of the undertaken activities and the requirement of complexity in body modelling. One should manage all areas in which an individual has the possibility to interfere. Simultaneously, in the case of patterns that are impossible to obtain or maintain for a long time, for example being tall or lacking signs of ageing, it is required to use techniques and tools that allow for masking imperfections (proper clothing, creams, hair colouring).

Besides, the broadest discussed way of disciplining the body in the discourse was physical activity, including exercise, sports, and an appropriate diet. Their function is to develop the musculature and counteract the fundamental barriers to a perfect body - obesity, health problems, low endurance, poor condition, and sexual performance, which are associated with a sense of shame and unattractiveness (Majer 2016: 203216).

An essential element of the discourse concerning physical exercise was the indication of genetic predispositions specific to each individual (Majer 2016: 219). Certain muscle groups may, therefore develop more slowly or quickly deplete their growth po- 
tential. Simultaneously, there is no direct indication that an attractive physique is not available to everyone. It is instead a demonstration of the variety of available methods and training plans, diets, and the need to adjust them individually.

All potential difficulties in disciplining the body - biological, psychological, and socio-economic (Majer 2016: 257) are presented as problems that can be counteracted by almost every individual, regardless of the circumstances. Physical activity is supposed to ensure that an individual can maintain an efficient, healthy, and well-cared body, therefore, mostly devoid of physical or aesthetic deficiencies.

Therefore, physical fitness is not identified in the discourse with the power to dominate other men, women, or the existence of so-called 'bastions of masculinity'. Although it does not directly follow from Majer's research, the bodily ideal enables one to indicate certain spheres of the individual's life that may have been neglected before, which can also be included in a specific gender order.

Significantly, any sphere that might cause tension and the resulting sense of shame, of not conform to expectations, is presented as a form of individual differentiation rather than inequality. Taking the effort to discipline the body, even with unsatisfactory results, provides a basis for increasing self-awareness and exploring more individual means of body shaping, rather than achieving low status in a hierarchy. This is crucial because some of the consequences of achieving low results from the body-transformation process (particularly those related to sexual performance) could provide a basis for questioning an individual's masculinity.

Simultaneously, in the discourse, there appear bodies defined as non-masculine. However, their evaluation stems from a lack of attempts to discipline or apply the process of transforming the body only to selected aspects. Individuals who take a comprehensive and intentional approach to body modelling may face criticism of their methods, but they are not expected to challenge their masculinity. This is significant because despite emphasizing the necessity of body modification, the models do not appear to be very oppressive towards the individual.

\section{CHARACTERISTICS OF MEN WHO REGULARLY EXERCISE AT THE GYM}

The disciplining of the male body, as Majer indicates, is mostly done through physical exercise in gyms. The necessity of constant, comprehensive, and intentional influence on the physique may suggest that in the case of a large proportion of men, participation in gyms is becoming an increasingly common practice. How physical exercising is presented in the discourse and the representations of individuals performing it can be contrasted with research on long-term gym members.

Research conducted by Tatiana Maciejewska (2014) indicates that disciplining the male body at the gym is a form of modelling the individual's visual self-representation to inscribe himself in the traditional discourse of masculinity. Respondents emphasized the importance of male authority among exercisers, relations of power and subordination, and the reproduction of the principle of hetronormativity (p. 85-86), thus elements relating to the concept of hegemonic masculinity (Connell 1995).

Physical exercises are presented as an activity that combines elements of slowly 
and consistently improving one's personality and simultaneously acquiring characteristics that symbolically communicate superiority over other men and their bodies' potential danger (Maciejewska 2014: 89). Therefore, the body is a symbol of strength and a high position in the system of gender inequality. Simultaneously, its visual presentation is expected to emphasize dominance, including readiness for physical confrontation.

Frequent and enthusiastic display of musculature, and therefore constant evaluation of work on the body may be a form of distinct emphasis on one's gender identity and at the same time, in the case of unsatisfactory results, also a cause for anxiety. The untrained or insufficiently trained body is embedded with characteristics that indicate weakness, non-masculinity, non-heteronormativity.

The depiction of male discipline in the accounts of regular gym members is much more oppressive than Majer's discourse analysis presents. Conducting it in relation to the hegemonic masculinities generates additional tensions that male exercisers must confront. Highly valued dominance over other men (with less attractive physiques, less training experience) tends to generate insecurities that are less concerned with the body itself, but instead with the actors' masculinity patterns.

Maciejewska defines the affirmation of one's masculinity through a muscular body as "a link between traditional, hegemonic masculinity and modernity" (ibid.: 91). The more outstanding picture of the discourse of disciplining the male body can be interpreted as aligned with a changing social reality that is increasingly open to androgyny and more concerned with the male body and its attractiveness. In Maciejewska's narrative, however, there is an intense contestation of the transformations that could weaken male dominance.

By imposing on the description of the discourse of disciplining the male body the characteristics of individuals who regularly attend gyms, it is possible to provide a fuller picture of masculinity's transformations. From this perspective, it may be an interesting development to include in the description the characteristics of bodybuilders, and therefore those individuals who, both from the perspective of their status in gyms and the conduct of a reflective body project, would appear to be the most advanced, and so may be described as experts.

\section{BODYBUILDING}

The aim of specific bodybuilding regimes is to achieve a physique characterized by extraordinary muscle mass while maintaining adequate (often exaggerated) body proportions, symmetry, and definition (visible separation between the muscle bellies). Therefore, the final shape and level of 'development' of the body are not a result of adapting it to specific activities or lifts. The performance consists of its presence in the best possible shape during competitions (Richardson 2012a: 21).

Numerous comparisons of bodybuilders with Greek sculptures are essential in the literature on the subject. Therefore, the process of aspiring to beauty and ideal body proportions, characteristic for the early stages of bodybuilding development, was indicated. However, since the 1980s, the dominant image of a bodybuilder was no longer 
identified with aesthetics, but rather with the desire to achieve an ever-larger body size. Athletes competing at the highest level illustrate the desire for a constant redefinition of what is considered possible in human physique development, not to conform to the canon of beauty (Liokafto 2017: 96).

The divergence from a narrative based on aesthetics concerning bodybuilders' bodies is particularly interesting from the perspective of the discussion of male body images and the results of Majer's analysis. The process of disciplining the body, in this case, seems to have a point where beauty and fitness are no longer relevant. The extraordinary body size is perceived as asexual. The athlete's ability to shape it and continuously increase his development potential begins to be a major category in the bodybuilding messages (Richardson 2012b: 146).

Therefore, it can be assumed that recipients of media materials containing bodybuilders' images will not consider them as direct references to socially expected ways of performing masculinity. Their significance will instead be derived from making credible the possibility of almost unlimited interference in the shape of one's physique. Simultaneously, transmissions presenting the process of body disciplining by bodybuilders may constitute a form of inspiration or instruction indicating specific necessary characteristics and practices that enable successful body shaping.

Recipients may interpret such messages as a form of reinforcement of their assumptions about their preferred gender performance. Representations of bodybuilding do not indicate the benefits of such an advanced body reshaping process; neither do they promote it as an aesthetic that conforms to the canon of beauty. The dominant cult of hypertrophy may inspire increasingly vast body disciplining practices without necessarily aspiring to achieve a bodybuilding physique.

From this perspective, deriving role models from bodybuilders' representations may exacerbate the tensions pointed out in discussing images of people who regularly exercise at the gym. Due to the niche nature of professionally practised bodybuilding, in the case of athletes for the vast majority of individuals, these will be physiques known only from the media. The hyperreal (Baudrillard 1983) myth of unlimited hypertrophy, which can be interpreted as a confirmation of the attainability of the expected physique by all men, can also generate unrealistic expectations of the body that symbolically indicate the hegemonic masculinity of a given individual.

The importance of the gym and exercising as fundamental implements for body shaping means that materials relating to bodybuilding can have a noticeable impact on how regimes are imposed on the body. Thereby, they may partially shape the discourse of disciplining the male body. Bodybuilding motivational videos are an exciting form of such messages. Their relevance will be necessary for those who regularly attend gyms. However, this type of material can also attract individuals who are just planning to begin transforming their bodies through exercise. Their appeal, therefore, cannot be reduced to merely reproducing or contesting hegemonic masculinity.

It is worth emphasizing that the athletes or bodybuilding federations do not prepare such videos, so they should not be considered as marketing materials. Their analysis cannot indicate if they present a real image of the practices being undertaken and the meanings given to them by the bodybuilders, nor will it make it possible to charac- 
terize the community of practice of bodybuilders. The materials should be regarded as idealization and promotion of individual attitudes and values by their authors, which means the discipline's fans.

Analysis of bodybuilding motivational films, assuming that they present a certain depiction of disciplining the body as conducting a reflective project, allows one to interpret this type of material as referring to physical exercise and other spheres of individual activity. This enables the present a set of expectations that are not limited to bodily ideals, but more broadly to ways of performing masculinity.

\section{RESEARCH METHODOLOGY}

The research material was collected using the most popular contemporary video sharing platform - YouTube.com. The criterion of popularity in selecting the medium was the intention to include in the research corpus materials with the most significant possible potential to reach the viewers. For this reason, it was not decided to use websites with bodybuilding themes, as it can be assumed that their recipients identify themselves as bodybuilders or aspiring to this status. Individuals looking for motivation or inspiration for exercises focused on improving body projects, rather than improving sports performance, will probably choose websites that give a sense of less formality or do not require significant cultural competence (for example, due to specific language).

The searched phrase was Bodybuilding motivation. The English term's choice was primarily determined by the intention to include the most famous content in the research corpus. The search mechanism does not require the searched phrase to be part of the film title, so it was decided to use the universal phrase available, which would be evident from the person's perspective by adding the video tag. In addition, the direct reference to bodybuilding made it possible to exclude materials relating to other disciplines from the results provided by the portal.

Two of the available search methods were applied during the selection of videos. The first one was the criterion of accuracy. The algorithm indicates the results best suited to the given phrase; the second criterion was the number of views (from the highest). Each time, the results were limited to the specified period (June 2018 - June 2019). The first twenty results from both searches were included in the research corpus. Video materials of the total length of about 3 hours and 10 minutes were collected in this way. The single material was between 3 and 10 minutes long.

A categorization key prepared under the inductive approach was employed to encode the collected videos. The specificity of the collected material forced separate coding of the visual and verbal layer of the message. This results from the way of creating this type of content. Films are formed by combining and reusing many short fragments from different sources. The athletes' speeches and fragments of interviews do not have to be directly related to the screen's characters. A standard procedure is also applying elements of motivational speeches, whose content is not related to sport.

In the qualitative analysis of content, a single video was taken as the analysis unit. 
Since most of the content was not limited to the presentation of a single athlete, and the dynamic editing made it impossible to divide it internally for example into scenes justifiably; the materials were treated as closed units. The purpose of the analysis was to indicate the image of the male body project presented in this type of transmission. Therefore, the findings can be considered relevant regardless of how the recipients evaluate the physiques presented in the movies. The values and norms communicated in the videos relating to the body modelling process can be considered attractive and valuable by individuals who do not aspire to such far-reaching body transformations.

\section{ANALYSIS FINDINGS}

The video materials constituting the research corpus presented the bodies of various athletes in many contexts. The gym was the dominant one; however, it should be emphasized that exercising men's physiques depicted different periods of possible preparations for competitions. Thus they did not always match the images known from the contest stage. In the case of motivational movies, the competition period is not a dominant image; one can also get the impression that it is not a culmination point for the undertaken efforts.

This implies that the movies' events do not have to be presented in chronological order or refer to the same athletes. Performances on stage may be interspersed with training fragments during the period of mass gain (when the physique loses its definition), and the competitors do not have to appear in any other context. Therefore it is challenging to identify presentations revealing training and victories in the form of cause and effect. An exception to this is the few clips that relate entirely to the career of one athlete.

It is worth emphasizing the selection of music constituting the background for watched athletes. The primary practice for movies focused mainly on training or sequences presenting this activity is to employ active fragments of cinematic soundtracks. Sounds associated with heroic struggle scenes, sometimes culminating in the film, allow to build additional suspense and symbolically emphasize the importance of the body design. Fast editing reminiscent of music videos or film duels, matched to the music, the timbre of the voice, and the messages transmitted by the contestants, highlighted screams and sounds produced by the training equipment make it possible for the viewer to get more involved.

While other themes are displayed on the screen, music does not have such an important role. Importantly, in movies where the creators do not use fragments of athletes' comments or motivational speeches, there was neither dynamic music nor a cinematic soundtrack. Considering the criterion of popularity employed in the process of collecting materials, it can be presumed that the recipients of this type of movie vary in terms of expectations, and visible in some productions pathos is not a fundamental element.

The conducted analysis enabled to identify of four elements used to create a male body project. These are (1) conditions essential for conducting the project, (2) tools used in the project, (3) methods of monitoring and evaluating the project, and (4) side 
effects of the project.

\section{Conditions essential for conducting the project}

One of the fundamental values emphasized in the movies was the work ethos. It is indicated as a necessary element, not only to succeed and achieve further milestones in the project but also to comply with the essential sacrifices and regimes imposed on the body. Therefore, its absence makes it impossible to start modelling the body in an advanced method that guarantees the expected results.

Bodybuilding project is portrayed as a superior element in the individual's values hierarchy. The necessary work ethos enables the realization of subsequent goals and stresses that body modelling should not be considered a hobby. It is a work ethic and systematic, I am not a "genetic freak", I get up at 3 a.m. and train from 4 a.m. It is not something I have been doing for a year, I have been doing it my whole life (T12). Therefore, transforming the body is not limited to cosmetic changes, and its importance should be considered central and have a significant impact on other spheres of individuals' activity. Simultaneously, indirect references to fatigue and the difficulty of incorporating body modelling practices into the daily routine show that undertaking a project requires permanent incorporation into one's daily life and full acceptance of all related inconveniences.

A long-term perspective is also emphasized. Focusing strongly on the work ethos allows one to think that body modelling is separated from temporary fashions and short-term trends. Full involvement in the project does not require specific goals. However, it demands a far-reaching commitment to the idea of constant, systematic, and slow physiological transformation. Significantly, there are many challenges associated with it, which should not only be accepted by individuals who transform their bodies but are an essential part of the whole process. The movies glorify the athletes' inconveniences considerably and emphasize their importance as a selection for the individuals starting to work on their bodies. You have to sacrifice everything you believe in, lose everything you care about, and go beyond that (W4).

The regimes imposed on the body and the related inconveniences presented in the movies go far beyond muscle sores, hunger-related to diet and body fatigue. The project will require an individual to sacrifice the small pleasures of everyday life and negatively affect his relationships with his environment, a possible feeling of loneliness and misunderstanding. Submitting to the process of body modelling means imposing on the sphere of free time the logic associated with work. Important in this context is that the transmissions do not indicate that this is a potential risk that the individual must take into account, but rather an immanent element of the process.

Another discomfort, which is permanently inscribed in the process of transforming the body, is the acceptance and glorification of the physical pain felt. I love to work out, I love torturing my body and causing it pain (T11). Transformation of the physique and related regimes are shown as a form of forcing the body to take a form that is not natural for it.

Directly presented difficulties that must be addressed by each individual conduct- 
ing the body project references to torture, resignation from engaging and valuable leisure activities create an image of the beginning of the process of modelling the body, as a choice between absolute sacrifice or resignation. The decision should be definitive and binding in this case. Therefore the space allowing for testing the tools of body transformation or only their partial use is eliminated. Either you decide to give everything you have or stay home (T1).

Furthermore, it should be emphasized that resignation from starting the project, even though it is associated with disapproval, is not associated with a significantly negative image. Body modelling allows for achieving one's full potential. You have to be disciplined, and you have to sacrifice a lot to live like this, few people are willing to do it, few people can put so much into it (T9). Individuals who do not transform their bodies are described as average. They are not considered unattractive or poorly maintained, but cannot undertake the work required by the body project.

The decision to conduct the body project is also limited by the requirement to stay entirely focused during all body modelling activities. The videos emphasize this through numerous sequences in which athletes calmly and methodically prepare the equipment used in the exercises and calm down before the next series of repetitions. Work on the body is done by entering two states, dynamic and explosive, characteristic for the moment of exercise and static. The athletes prepare mentally and physically for the next effort.

The videos do not represent scenes in which athletes interact with other space users. You need to be focused, you have work to do, they can talk and scream, but if you are working out you need to be focused, you will talk outside (T11). The only exception to this rule is the limited number of training partners or coaches, but also, in that case, the athlete does not directly refer to them verbally and does not maintain eye contact. Therefore, the body transformation practices are a sphere of activity of the individual, which should remain inaccessible to other people. There are numerous motives for going to the gym or crossing its threshold, as a symbolic disconnection from other responsibilities and complete dedication to modelling.

This way, the image of modelling the body as a "lonely path" is emphasized, but so is the necessity of constant control over every aspect of the project, full of immersion. Any external factors may be disturbances that will negatively influence the efficiency with which the individual transforms his physique. That is why such important and underlined in the videos are all the moments when, after performing a challenging exercise, often visible grimaces of pain and heard screams, athletes regain concentration and balance almost immediately.

\section{Tools used in the project}

The fundamental tools for body modelling are physical exercises. Strength training is presented in a manner that is primarily to evoke admiration and emphasize athletes' extraordinary strength. A vital element of these representations is that the creators never specify the actual number of lifted kilograms. Weights, which fills almost all the space available on the barbell, bending them and the sounds of the equipment 
being placed back, symbolically communicate that one can observe the performance reserved for the strongest individuals.

More important than the number of kilograms appears to be the exercise method. Almost all series are presented in a manner that provides the impression of performing them on submaximal weights. The athletes often train until the muscle fails, that is, the moment when the next repetition is not possible; and beyond that when the next moves take place with the assistance of a training partner.

This is significant because the viewer's attention is focused on a sphere that is not easily quantifiable. The recipient observes a model in which expectations are not based on directly expressed numbers, which suggests that the goals should be regularly and consistently adjusted, and the focus on the load being used will only blur the image of the effort put in by the athlete.

Therefore, the efficient use of tools in the project is a prerequisite for the transformation of the body to take place following the potential and the desired pace of change. Significantly, modelling is also burdened with substantial inconveniences, the severity of which may increase with the degree of involvement and development of the body project. Their underestimation during the exercises is a reference to appropriate mental preparation, not to overcome them.

Another tool that allows the body project to be carried out efficiently is diet. The diet is presented as a form of significant sacrifice, which requires discipline and determination from the individual. In the process of body modelling, the pleasure of eating is, in fact, unavailable. During the day, the food consumed must provide the body with a precisely specified number of calories, micro, and macronutrients. This is associated with perseverance and the need to have the relevant competencies to control and modify the dietary assumptions constantly. When it comes to diet, micro-improvement, and sacrifice, it separates gym rats from bodybuilders (W17).

Regardless of the stage of body modelling, references to diet always indicate some challenges. During muscular growth, the volume is high: 10 - 12 meals a day, this is the time of mass gain (W16), when the level of adipose tissue is reduced, athletes complain of felt hunger continuously. In every case, the consistency and precision with which athletes approach the food are essential. The authors of the videos emphasize this by focusing the viewer's attention on plastic containers with self-prepared meals. The person eating, in this case, is less important than the food itself. People ask me - how do you keep this form? It's easy; you have to eat like a dog (T9).

Therefore, monotony in the diet is presented as a positive factor, which facilitates the consistent application of the regime. It is also an example of the primacy of the project over other areas of individual activity. While training takes place in a particular space and can be separated from other life fields, maintaining dietary rigour requires additional preparation and often interference with other practices. The videos present fragments in which the athletes interrupted their non-sporting activities to have a meal at the designated time, regardless of the place and circumstances in which they were placed.

Another tool inextricably associated with the body project is aerobic exercises. They are presented primarily in the form of walking on a treadmill or training stairs. 
Significant in this respect is that such activities, although shown as necessary for body shaping, are primarily a sphere of mental development. Their specificity consists of the necessity to perform monotonous, non-engaging exercises that do not allow the body's potential or to test their limits.

An essential element of body modelling is the constant increase in knowledge regarding all the project's practices and activities. Athletes are largely presented according to the image of a self-made man. The videos do not refer to formal education, courses, or university studies, but rather show the need for specific know-how, the scope of which will strongly depend on the characteristics of a given organism, its genetic potential.

It is worth emphasizing that some elements could have been present in the messages, but the authors did not include them in any movie. There was no reference to the processes of medicalization and cyborgisation of the body in the analyzed material. This gives an image of projects which do not need anabolic steroids, implants, extensive supplementation, or special health care to achieve the assumed outcomes.

\section{Methods of monitoring and evaluating the project}

The way to control the level of involvement in exercises is to observe the body. The expected reaction is dizziness, nausea, and even blackouts. If your body does not struggle back, it means that something is not right - you have not yet exercised hard enough (T12). Valuable are those activities that have been brought to an extreme form. Athletes are often portrayed in the movies when they move in a wobbly step after exercise or lying exhausted on the ground.

Another indicator of effectiveness in modelling physique is pain. What is important, it has no diagnostic function, so it does not indicate the risk of injury, improper form, or excessive fatigue. It is presented as a permanent exercise element because the relevant work to build muscles starts only when the discomfort starts to be noticeably unpleasant. I do not count all squats, I start to count when I feel pain (T3).

Another temporary way to control the effects of work is to pose in front of the mirror after the exercise or training. What is important is that it is not only characteristic for athletes with low levels of body fat and does not require removing elements of clothing. The sportsman does not pose in front of the other exercising people, nor does the movies show their reactions. The presentation of the muscles is not intended to impress or to evoke a specific impression. Therefore, the body during modelling should meet the requirements and expectations set only by the person transforming it. The way it is valued in public space should not be perceived as significant.

The posing can also take place on stage, but its meaning is much more symbolic. The movies use almost exclusively fragments of Mr. Olympia's competition, one of the most prestigious. What is essential is that the participation in the competition or even the victory is not presented as a reward for the sacrifices or the crowning of a long work period.

The competition motif is also used in dynamic montages, in which heavy exercises with posing on stage are interwoven. Since both activities do not refer to the same 
athlete, such a procedure can be interpreted in two ways. The first one is the need to have a point of reference in the project, other individuals, whose body confirms the availability of the effects assumed by the modelling physique. The second interpretation is the need to evaluate the project after a more extended period. This makes it possible to determine the effectiveness of the tools used and the extent to which the physique assumptions have been fulfilled.

Therefore, participation in the competition does not mean the end of the body project or even its interruption. It should be treated as a functional element of it, which does not require reducing or stopping the body's regimes. Instead, it is a moment to set even more restrictive forms of body modelling so that the physique can continue to develop. Therefore, victory and defeat are only indicators of the effectiveness of the tools used or the lack of it.

Also crucial for body project control is the fact that you should never be satisfied with your physique. Knowing one's weaknesses allows one to rationalize the project and make it easier to impose more regimes on the body. Following the logic of unlimited possibilities, satisfaction with the figure means withdrawal from the project, and therefore not reaching its maximum potential and symbolic inclusion into the category of ordinary people.

\section{Side effects of the body project}

The videos refer to possible side effects of the body modelling process, but their spectrum is quite limited. They are only injuries resulting from a specific way of training. Muscle tearing was indicated as particularly harmful because it disrupts the aesthetics of the body and leads to its imbalance. In this case, the viewer's attention is primarily focused on the injuries of the shoulder muscles, biceps, and triceps. This emphasizes the particular importance of muscular arms in the male figure.

Significant injuries are presented as elements that slow down body development but never completely stop it. The project is carried out despite all the difficulties. There are no breaks for convalescence, but almost immediately, alternative training methods are sought. The muscle damage is shown as a new body imperfection that has to be adequately worked out; medical treatment would stop the body transformation process.

The only exceptions to this standard are surgeries. When it is necessary to conduct them, the exercises are stopped, but the movie authors emphasize that this is the time to develop a new training plan and assumptions for other regimes, which will allow one to restore the proportions and desired appearance of the body in the shortest possible time.

Injuries that do not affect the body shape but only constitute discomfort during exercise are entirely underestimated. The pain they cause is an inherent part of the project and, as was indicated, must be accepted in order to achieve the full potential of the body. The worst pain I ever felt was when a huge dumbbell fell on my big toe and broke it. This did not interrupt my training, I went back to the gym the next day and did some squats (W7). 


\section{DISCUSSION AND CONCLUSION}

The image of the reflexive body project presented in motivational bodybuilding films can be referred to as the process of transformations of masculinities, indicating how this type of content can influence individuals' interpretations of the significance, potential tools, and consequences of disciplining the body due to the pressures of achieving masculine body ideals. Therefore, by assuming that the discourse of disciplining the male body is one of the discourses shaping individuals' gender identities, it is possible to describe a specific segment of it that can influence the shape of socially approved ways of performing masculinity.

The work ethos, strongly emphasized in the films, provides a rebound of Majer's description of men's need to take a comprehensive and intentional approach to enhance their bodily attractiveness. Narratives based on strongly accentuated sacrifice and the imposition of a work-related logic on activity provide an image of the importance of the pressure of male bodily ideals. Striving to conform to them can be interpreted as a necessity and require a commitment on many levels. Therefore, the messages can be understood as emphasizing any areas in which there may be tensions in the individual related to not being able to fulfil a beautiful body's demands.

This provides an image of masculinities in which insecurity is permanently inscribed, related to the expectations concerning the manner of its performance. The disciplining of the body, which should not be considered a hobby of the individual but one of the key elements constructing his identity, symbolically may be interpreted as a strong pressure to constantly analyze the expectations concerning one's actions and to avoid any situation in which the actor would be exposed to social ostracism.

Simultaneously, underlying both the performativity of gender and the reflexive project of the body is the assumption of the subjective role of the individual. Both the modes of disciplining the body and the image of performing masculinities are not grounded entirely in the expectations and pressures of society. This is illustrated in the instance of motivational films by the possibility of negative relations with the environment, which involves non-participation in certain spheres of activity rather than exposing the actor to ostracism. Therefore, the individual may adopt a strategy of avoiding contexts in which gender performance patterns he finds attractive could be negatively evaluated. Furthermore, when it is not possible to meet external expectations, maintaining a coherent gender identity image may involve reflexive restriction of one's spheres of activity.

It should be emphasized that the narrative presented in the films does not present negative images of individuals who do not undertake or are not successful in disciplining the body. Failure to fulfil the expectations associated with the pressure to aestheticize the male body will therefore not be a foundation for undermining the actor's masculinity, symbolically linking him to femininity or inferior masculinity.

The other significant element of the narrative is the way emotions are expressed. Their depiction promotes withdrawal in the affective sphere. This is particularly interesting in relation to the previously mentioned tensions and insecurities inherent in masculinities' image. The recipient may have the impression that these are not ne- 
gated, but their influence on the actor's way of functioning is intentionally minimized. Therefore, working on the body is presented as an area where there should be no room for uncertainty; simultaneously, it does not provide pleasure or pride. Compliance with social expectations is portrayed as a form of minimizing potential disadvantages rather than achieving distinct benefits.

Majer's emphasis on the complexity with which men should address body discipline, from the perspective of motivational films, may equally indicate an increasing number of tension-producing areas. They associate an intensified commitment to body discipline with an increasing number of inconveniences for the individual. Significantly, in the narrative, actors do not eliminate or overcome them but merely adapt to their occurrence.

In this regard, the element of continually interpreting changing expectations over time regarding how to perform gender is essential. The messages indicated the necessity of continuously expanding knowledge regarding body transformation techniques and adjusting the exercises performed to the body's current predispositions. One can also refer to the expectations and pressures changing in time about the ideals of male corporeality and the modes of performing masculinity. Awareness of them and constant monitoring enables one to function more efficiently and avoid the aforementioned negative judgments and ostracism. Their occurrence, however, should not be interpreted as a failure, but as a lesson that allows the individual to become more reflexive.

The last of the most important narrative elements is the low importance that the authors of the messages gave to mutual comparisons between men. The recipient may interpret this as a dismissal of the need for men to compete for both in terms of the attractiveness of their bodies and the types of masculinity presented. When made, the comparisons may be intended to discern the individual's inadequately addressed areas of his activities rather than to create a hierarchy.

The research indicates that the discourse of disciplining the male body portrays images of masculinities as strongly associated with the presence of anxieties and insecurities. The analyzed materials portray body projects in a way that relates to the negation of the process of increasingly subjecting the male body to evaluations in public space. Body modelling should be primarily a sphere of character improvement, secondarily of physique transformation. Therefore, its presentation cannot be motivated by the desire to gain benefits or impress other individuals.

The specific training methods emphasizing strength, the ability to control both the body and the surroundings, may indicate that the motivational films constitute a space for reproducing images culturally considered traditionally masculine. Simultaneously, the reproduction of male dominance is not alluded to by any means, nor is the attraction of hegemonic masculinity, which was a crucial element in Maciejewska's analysis.

The more appropriate interpretation, therefore, would suggest that the bodybuilding motivational films are a fragment of the discourse of disciplining the male body, which will indicate that men and how they perform their masculinities are adapting to, as opposed to rejecting, changing social reality as well as new expectations and pressures. References in the videos to culturally considered characteristics to be tra- 
ditionally masculine will only be evidence of the slow tempo of the transformation process.

FUNDING: This research received no external funding.

CONFLICT OF INTEREST: The author declares no conflict of interest.

\section{REFERENCES}

Arcimowicz, Krzysztof. 2015. “Współczesny ideał męskiego ciała - wybrane aspekty problematyki.” Folia Sociologica 55: 57-76.

Baudrillard, Jean. 1983. Simulacra and Simulation. Michigan: University of Michigan Press.

Berggren, Kalle. 2014. "Sticky Masculinity: Post-structuralism, Phenomenology and Subjectivity in Critical Studies on Men.” Men and Masculinities 17(3): 1-22.

Bowman, Paul. 2020. "In toxic hating masculinity: MMA hard men and media representation." Sport in History 40(3): 395-410.

Bridges, Tristan S. 2009. “Gender Capital and Male Bodybuilders.” Body \& Society 15(1): 83-107.

Butler, Judith. 1990. Gender Trouble. Abingdon: Routledge.

Connell, Raewyn W. 1995. Masculinities. Berkeley: University of California Press.

Deutsch, Francine M. 2007. “Undoing gender.” Gender and Society 21: 106-127.

Dziuban, Agata. 2013. Gry z tożsamością. Tatuowanie ciała $w$ indywidualizującym się społeczeństwie polskim. Toruń: Wydawnictwo Naukowe Uniwersytetu Mikołaja Kopernika.

Foucault, Michel. 1990. The History of Sexuality. Vol. 1, The Will to Knowledge. Harmonds-worth: Penguin.

Giddens, Anthony. 2001. Nowoczesność i tożsamość. Warszawa: Wydawnictwo Naukowe PWN.

Liokafto, Dimitris. 2017. A genealogy of male bodybuilding: from classical to freaky. New York: Routledge.

Maciejewska, Tatiana. 2014. „Siłownia jako miejsce konstruowania męskiej tożsamości cielesnej.” Ars Educandi 11: 79-95.

Majer, Anna. 2016. Dyskurs dyscyplinowania męskiego ciała w wybranych tekstach kultury popularnej. Gdańsk: Wydawnictwo Naukowe Katedra.

Richardson, Niall. 2012a. "What is the 'Practice' of Bodybuilding?” Pp. 21-29 in Critical Readings in Bodybuilding, edited by A. Locks and N. Richardson. New York: Routledge.

Richardson, Niall. 2012b. “Bodybuilding as Representation.” Pp. 143-151 in Critical Readings in Bodybuilding, edited by A. Locks and N. Richardson. New York: Routledge. 
Shilling, Chris. 2003. The Body and Social Theory. London: Sage.

Staniec-Januszek, Ewa. 2019. „Zastosowania nowoczesnej biotechnologii z perspektywy ciała jako projektu." Rozprawy Społeczne 13(2): 129-141.

West, Candace \& Don H. Zimmerman. 1987. “Doing Gender.” Gender and Society 1(2): $125-151$.

Wolf, Naomi. 2014. Mit urody. Warszawa: Wydawnictwo Czarna Owca.

\section{BIOGRAPHICAL NOTE}

Kacper Madej is PhD student at the Faculty of Sociology, Adam Mickiewicz University in Poznań. His research interests oscillate among sociology of body, sociology of sport and gender studies.

OPEN ACCESS: This article is distributed under the terms of the Creative Commons Attribution Non-commercial License (CC BY-NC 4.0) which permits any non-commercial use, and reproduction in any medium, provided the original author(s) and source are credited. 